Available online at website :

http://uinjkt.ac.id /index.php/elementar

Elementar (Elementary of Tarbiyah): Jurnal Pendidikan Dasar, 1(1), 2021, 59-67

\title{
Pengaruh Media Pembelajaran Zoom terhadap Hasil Belajar PPkn Siswa Kelas IV MI Al-Wathoniyah 43 Jakarta Utara
}

\author{
Mimi Jamilah $^{1)}$, Rohmat Widiyanto ${ }^{2)}$ \\ Pendidikan Guru Madrasah Ibtidaiyah, FITK, UIN Jakarta \\ Jl. Rorotan IX No 17, Kota Jakarta Utara \\ E-mail: Mimijamilah1998@gmail.com
}

\section{Corresponding}

Author: Mimi Jamilah ${ }^{1)}$,

Rohmat Widiyanto ${ }^{2}$

Submit: 27 Agustus 2020

Revisi: 10 November 2020

Approve: 30 Januari 2021

Pengutipan: Mimi Jamilah

\& Rohmat Widiyanto.

(2021). Pengaruh Media

Pembelajaran Zoom

terhadap Hasil Belajar PPkn

Siswa Kelas IV MI Al-

Wathoniyah 43 Jakarta

Utara. Elementar (Elementary

of Tarbiyah): Jumal Pendidikan

Dasar, 1(1), 2021， 59-67.

elementar.v1i1. 20886.

\section{Abstract}

This study aims to determine how student learning outcomes on Pancasila material using Zoom learning media and is there an effect of Zoom learning media on learning outcomes ini the aspects of knowledge on Pancasila material. The research method used a quasi-experimental desaign with Nonequivalent control group design. The sample taken was class IVA with a total of 10 students. the instrument used was a test instrument in the form of multiple choice questions and non-test in the form of a questionnaire. Based on the data analysis, the student learning outcomes were obtained. With the results of the hypothesis on the posttest data, it shows that the data processing uses hypothesis testing (ttest) using the SPSS program which obtains a value (sig.2-tailed) with a significance level of $5 \%(0,05)$. The results of hypothesis testing (t-test) show the final result that $\mathrm{Ho}$ is rejected and $\mathrm{Ha}$ is accepted. The average learning outcomes of students who use Zoom learning media are higher than the average learning outcomes without using Zoom learning media. And based on the result of non- test data analysis based on student responses to learning media Zoom with percentage value of $86 \%$.

Keywords: Zoom, Student Learning Outcomes, Learning Media.

\begin{abstract}
Abstrak
Penelitian ini bertujuan mengetahui bagaimana hasil belajar siswa pada materi Pancasila menggunakan media pembelajaran Zoom dan Adakah pengaruh media pembelajaran Zoom terhadap hasil belajar aspek pengetahuan pada materi Pancasila. Metode penelitian ini digunakan adalah kuasi eksperimen dengan disain Nonequivalent control Group Design. Sampel yang diambil adalah kelas IVA dengan jumlah 10 siswa. Instrumen yang digunakan instrumen tes berupa soal pilihan ganda dan non-tes berupa angket. Berdasarkan analisis data diperoleh hasil belajar siswa PPKn. Dengan hasil hipotesis terhadap data postest menunjukan pengolahan data menggunakan pengujian hipotesis $(u j i-t)$ menggunakan program SPSS yang memperoleh taraf signifikansi 5\% $(0,05)$. Hasil pengujian hipotesis $(u j i-t)$ tersebut menunjukan hasil akhir bahwa Ho ditolak dan Ha diterima. Rata-rata hasil belajar siswa yang menggunakan media pembelajaran room lebih tinggi dibandingkan rata-rata hasil belajar tanpa menggunakan media pembelajaran zoom. Dan berdasarkan hasil analisis data nontes berdasarkan respon siswa terhadap media pembelajaran zoom dengan nilai persentase $86 \%$.
\end{abstract}

Kata kunci: Zoom, Hasil Belajar Siswa, Media Pembelajaran. 


\section{PENDAHULUAN}

Pembelajaran adalah proses interaksi peserta didik dengan pendidik dan sumber belajar pada suatu lingkungan belajar. Dengan kata lain, pembelajaran adalah proses untuk membantu peserta didik agar dapat belajar dengan baik, proses pembelajaran dialami sepanjang hayat seorang manusia serta dapat berlaku di manapun dan kemanapun. (Suardi, 2012).

Pelaksanaan pembelajaran merupakan hasil integrasi dari beberapa komponen yang memiliki fungsi tersendiri dengan maksud agar ketercapaian tujuan pembelajaran dapat terpenuhi. Ciri utama dari kegiatan pembelajaran adalah adanya interaksi. Interaksi yang terjadi antara peserta didik dan lingkungan belajarnya. (Rusman, 2017).

Interaksi yang terjadi antara siswa dan lingkungan belajarnya. Salah satu hal yang menyebabkan rendahnya hasil belajar siswa pada pandemi seperti ini, yaitu kurang memaksimalkan penggunaan media pembelajaran dalam membantu penyampaian materi ajar. Peran media pembelajaran sangat penting dalam proses pembelajaraan. Karena media merupakan salah satu dari komponenkomponen pembelajaran. Berdasarkan masalah yang peneliti temukan setelah melakukan wawancara dengan guru wali kelas IVA di MI Al-Wahoniyah 43 Jakarta Utara. Tentang hasil belajar yang mana masih banyak siswa yang memperoleh nilai rata-rata 75 bahkan masih banyak yang memperoleh nilai dibawah 75, rendahnya hasil belajar siswa disebabkan kurang minta siswa mengulang pelajaran ketika dirumah. Saat ini guru menggunakan media E-learning yang sudah diterapkan disekolah tersebut untuk pembelajaran jarak jauh, guru menjelaskan bahwa media E-learning tersebut terdapat bahan ajar, pemberian tugas untuk siswa dan video pembelajaran.

Namun, kebanyakan guru-guru jarang sekali menerapkan video pembelajaran di elearning, karena masih banyak guru yang kurang menguasai media tersebut. Dalam media ini guru tidak bisa menjelaskan materi terlebih dahulu, guru juga tidak bisa mengajar tatap muka, karena itu siswa kesulitan untuk memahami materi pelajaran terutama pelajaran PPKn. Mungkin media tersebut baru-baru ini diterapkan pada pandemi seperti ini. Seharusnya pada saat pandemi seperti ini, Siswa sangat membutuhkan media yang inovatif itu sangat penting agar minat belajar siswa menjadi tidak rendah dan hasil belajar siswa menjadi meningkat. Perlu adanya suatu media yang bisa meningkatkan minat belajar siswa pada saat pandemi seperti ini. Menurut Permendikbud dalam proses pembelajaran bersifat interaktif dan menginspirasi. Untuk bisa mengajak peserta didik agar bisa berinteraksi dan aktif dalam pembelajaran, pendidik dituntut untuk menggunakan pendekatan, metode, media dan strategi 
pembelajaran yang menarik dan bervariasi. (Ramen, dkk, 2020).

Dengan ini menyadari pentingnya media pembelajaran zoom yang berguna pada saat pembelajaran jarak jauh terhadap hasil belajar peserta didik, dalam Susunan Artikel Pendidik dalam judulnya " Pemanfaatan Zoom Meeting untuk Proses Pembelajaran pada Masa Pandemi Covid-19”. Menjelaskan bahwa room ini dinilai praktis dan efisien pada saat pandemi seperti ini, karena itu aplikasi ini diharapkan dapat membantu seorang pelajar dalam pembelajaran berbasis online. Maka dengan ini penulis memilih judul " Pengaruh Media Pembelajaran Zoom Terhadap Hasil Belajar Ppkn Siswa Kelas IV MI AlWathoniyah 43 Jakarta Utara".

Belajar adalah suatu proses perubahan di dalam kepribadian manusia dan perubahan tersebut ditampakan dalam bentuk peningkatan kualitas dan kuantitas tingkah laku seperti peningkatan kecakapan, pengetahuan, sikap, kebiasaan, pemahaman, keterampilan, daya pikir, dan lain-lain kemampuan.yang sangat perlu kita garis bawahi adalah bahwa peningkatan kualitas dan kuantitas tingkah laku seseorang diperhatikan dalam bentuk bertambahnya kuantitas dan kualitas tingkah laku seseorang diperhatikan dalam bentuk bertambahnya kualitas dan kuantitas kemampuan orang itu dalam berbagai bidang. Jika dalam suatu proses belajar seseorang tidak mendapatkan suatu peningkatan kualitas dan kuantutas kemampuan, dapat dikatakan orang tersebut sebenarnya velum mengalami kegagalan di dalam proses belajar. (Thursan Hakim, 2010).

Menurut Gagne, Briggs, dan Wagner dalam Udin S Winataputra Pembelajaran adalah serangkaian kegiatan yang dirancang untuk memungkinkan terjadinya proses belajar siswa. Sedangkan menurut UU Nomor 20 Tahun 2003 tentang sisdiknas, jadi, pembelajaran adalah proses interaksi peserta didik dengan pendidik dan sumber belajar pada suatu lingkungan belajar.pembelajaran merupakan bantuan yang diberikan pendidik agar dapat terjadi proses pemerolehan ilmu dan pengetahuan. Maka dari itu, dapat dikatakan teori belajar merupakan upaya untuk mendeskripsikan bagaimana manusia belajar, sehingga membantu kita semua memahami proses inherm yang kompleks dari belajar. (Thursan Hakim, 2010).

Menurut Gagne, Briggs, dan Wagner dalam Udin S Winataputra Pembelajaran adalah serangkaian kegiatan yang dirancang untuk memungkinkan terjadinya proses belajar siswa. Sedangkan menurut UU Nomor 20 Tahun 2003 tentang sisdiknas, jadi, pembelajaran adalah proses interaksi peserta didik dengan pendidik dan sumber belajar pada suatu lingkungan belajar.pembelajaran merupakan bantuan yang diberikan pendidik agar dapat terjadi proses pemerolehan ilmu dan pengetahuan. Maka dari itu, dapat dikatakan teori belajar 
merupakan upaya untuk mendeskripsikan bagaimana manusia belajar, sehingga membantu kita semua memahami proses inherm yang kompleks dari belajar. (Thursan Hakim, 2010).

Menurut Gagne, Briggs, dan Wagner dalam Udin S Winataputra Pembelajaran adalah serangkaian kegiatan yang dirancang untuk memungkinkan terjadinya proses belajar siswa. Sedangkan menurut UU Nomor 20 Tahun 2003 tentang sisdiknas, jadi, pembelajaran adalah proses interaksi peserta didik dengan pendidik dan sumber belajar pada suatu lingkungan belajar.pembelajaran merupakan bantuan yang diberikan pendidik agar dapat terjadi proses pemerolehan ilmu dan pengetahuan. Maka dari itu, dapat dikatakan teori belajar merupakan upaya untuk mendeskripsikan bagaimana manusia belajar, sehingga membantu kita semua memahami proses inherm yang kompleks dari belajar. (Thursan Hakim, 2010).

Ibrahim dkk, menyatakan media pembelajaran adalah segala sesuatu yang digunakan untuk menyalurkan pesan (bahan pembelajaran) sehingga dapat merangsang perhatian, minat, pikiran dan perasaan siswa dalam kegiatan belajar untuk mencapai tujuan pembelajaran tertentu. (Usep Kustiawan, 2016).

Aplikasi Zoom adalah alat komunikasi yang menggunakan video dana dapat digunakan dalam berbagai perangkat baik seluler maupun desktop. Aplikasi ini biasanya digunakan untuk melakukan tatap muka secara jarak jauh dengan jumlah siswa yang cukup banyak. (https://trikinet.com/post/apa-itu-zoom). Dan Zoom merupakan sebuah layanan konferensi video yang memiliki kemampuan praktis dalam menghadirkan suasana meeting secara daring. ( Mursyid Kasmir, 2020).

Aplikasi ini tidak hanya digunakan untuk pembelajaran saja tetapi bisa digunakan untuk urusan perkantoran maupun urusan lainya. Platfrom ini gratis jadi dapat digunakan oleh siapapun dengan batas waktu empat puluh menit dan tidak ada batasan waktu jika akun kita berbayar. Dalam aplikasi zoom ini kita bisa berkomunikasi langsung dengan siapapun lewat video. Oleh karena itu, memang cocok digunakan sebagai media pembelajaran. (Dani Haqien \& Aqilah Afiifadiyah Rahman, 2020).

\section{Adapun Cara Pemakaian Aplikasi Zoom}

1) Guru mempersilahkan siswa untuk mengunduh aplikasi room melalui bimbingan dari kedua orangtuanya. Aplikasi zoom dapat digunakan melalui handphone atau laptop.

2) Siswa memasukan ID dari guru yang telah diberikan kata sandi dan ID dalam meeting atau mengundang lewat email.

3) Setelah masuk, semua siswa dapat berkomunikasi untuk berdiskusi dan memperhatikan penjelasan dari guru

Melalui room dijadikan pembelajaran jarak jauh menjadikan pembelajaran lebih efektif. Hal ini karena zoom menyediakan video konfrensi yang dapat dijangkau oleh seluruh partisipan atau siswa atau guru. Rekaman video pun terjaga keamananya dan 
memiliki fiturchatting sehingga jika ada yang mendapatkan pendengaran dengan baik pada saat video konferensi maka dapat berbicara melalui chatting. Dalam room dapat pula dilakukan penjadwalan meeting berikutnya yang akan dilakukan. Dengan memanfaatkan pembelajaran online ini, tentunya menjadi solusi yang sangat inovatif di tengah pendemi Covid 19 yang menuntut masyarakat untuk work from home.

Hasil belajar merupakan salah satu diantara tolak ukur yang menjadi acuan dalam memperbaiki kinerja seorang pendidik dalam penyelenggaraan proses pembelajaran. Bahkan, tidak sedikit yang berpendapat bahwa hasil belajar merupakan salah satu yang menjadi tolak ukur keberhasilan pendidik meskipun proses atau aktivitas peserta didik dalam proses pembelajaran tidak dapat juga untuk diabaikan sesuai dengan karakteristik kurikulum 2013 yang sedang dilaksanakan kala ini. ( Rahmat putra, 2018).

Pendidikan kewarganegaraan adalah mata pelajaran yang digunakan sebagai wahana

\section{METODE}

Penelitian Quasi Eksperimen (Eksperimen Semu) ini melibatkan dua kelompok yaitu kelompok eksperimen dan kelompok kontrol. Kelompok eksperimen adalah kelompok yang mendapatkan perlaku yaitu kelompok siswa yang mengikuti pembelajaran dengan menggunakan metode eksperimen, sedangkan kelompok kontrol untuk mengembangkan dan melestarikan nilai luhur dan moral yang berakar pada budaya bangsa indonesia. Nilai luhur dan moral ini diharapkan dapat diwujudkan dalam bentuk perilaku kehidupan siswa sehari-hari, baik sebagai individu maupun anggota masyarakat dan makhluk ciptaan Tuhan Yang Maha Esa, yang merupakan usaha untuk membekali siswa dengan pengetahuan dan kemampuan dasar berkenaan dengan hubungan antara warga dengan negara serta pendidikan pendahuluan bela negara agar menjadi warga negara yang dapat diandalkan oleh bangsa dan negara.

Dalam pendidikan kewarganegaraan ini diharapkan mampu membina dan mengembangkan anak didik agar menjadi warga negara yang baik (good citizen). Menurut Somantri warga negara yang baik adalah warga negara yang tahu, mau dan mampu berbuat baik. Adapun menurut Winataputra warga negara yang baik adalah yang mengetahui, menyadari dan melaksanakan hak dan kewajiban sebagai warga negara. (Ahmad Susanto, 2013).

adalah kelompok yang tidak mendapatkan perlakuan yaitu kelompok siswa yang mengikuti pembelajaran tanpa menggunakan metode eksperimen.

Desain yang digunakan dalam penelitian ini yaitu Quasi Ekesperimental Design bentuk Nonequivalent Control Group Design. Desain ini hampir sama dengan Pretest-Posttest 
Control Group Design. Dalam desain ini, baik kelompok eksperimen dan kelompok kontrol dibandingkan, kelompok tersebut dipilih dan ditempatkan tanpa melalui randaom. Dua kelompok yang diberi pretest untuk mengetahui keadaan awal untuk melihat perbedaan antara kelas eksperimen dan kelas kontrol. Hasil pretest yang baik yaitu jika nilai pretest kelas eksperimen dan kelas kontrol tidak berbeda secara siginifikan. Desain ini terbentuk.

\section{Pola Nonequivalent Control Group}

Design. Pada penelitian ini teknik pengumpulan data yang digunakan adalah teknik tes dan notes. Jenis teknik tes digunakan sebagai tes hasil belajar, yaitu tes untuk mengukur pencapaian seseorang setelah mempelajari sesuatu. Tes hasil belajar ini diperoleh dari hasil pretest dan posttest siswa. Adapun jenis penggunaan media pembelajaran zoom.

Instrumen tes adalah pengukuran hasil belajar yang mengukur kognitif digunakan alat ukur tes. Tes merupakan salah satu alat yang digunakan untuk mengukur pengetahuan peserta didik dalam proses belajar mengajar. Tes juga digunakan untuk mengukur keterampilan-keterampilan dari peserta didik. Maka dari itu, tes dapat

\section{HASIL DAN PEMBAHASAN}

Berdasarkan penelitian yang dilakukan, diperoleh data penelitian yang menunjukan adanya pengaruh signifikan dikatakan sebagai alat untuk mengumpulkan informasi-informasi salah satu objek.

Djemari mengemukakan, tes merupakan salah satu bentuk instrumen yang digunakan untuk melakukan pengukuran. Yang memiliki jawaban benar atau salah atau semua benar atau sebagai benar.

Instrument nontes merupakan instrumen yang digunakan untuk menghimpun data atau informasi yang dilakukan melalui pengamatan atau dengan memberikan respons langsung terhadap pertanyaan-pertanyan yang diajukan. Pengumpulan informasi dengan cara non tes, biasanya digunakan untuk mengukur afektif atau psikomotorik seseorang, sehingga pertanyaan lebih kepada pengamatan terhadap aspek yang dinilai.

Pada penelitian ini, angket digunakan untuk mengetahui respon siswa mengenai penggunaan media pembelajaran Zoom dalam proses pembelajaran PPkn. Angket yang digunakan dalam penelitian ini adalah model angket Skala Likert yang berbentuk ratingscale, dimana siswa memberikan respon terhadap pertanyaan-pertanyaan dengan pilihan yaitu STS (Sangat Tidak Setuju), TS (Tidak Setuju), C (Cukup), S (Setuju).

pada penggunaan media pembelajaran zoom terhadap hasil belajar ppkn siswa kelas IV MI Al-Wathoniyah 43 Jakarta Utara, 
dibandingkan dengan penggunaan model konvesional. Hal tersebut dapat dilihat dari nilai rata-rata kelas eksperimen lebih besar dibandingkan nilai rata-rata hasil belajar pada kelas kontrol, secara keseluruhan peneliti sajikan pada tabel di bawah ini :

Tabel 1. Rata-rata Hasil Belajar Ppkn Siswa Kelas Eksperimen dan Kelas

Kontrol

\begin{tabular}{lll}
\hline Kelas & Pretest & Posttest \\
\hline Eksperimen & 65,20 & 91,00 \\
Kontrol & 68,00 & 82,40 \\
\hline
\end{tabular}

Berdasarkan tabel nilai rata-rata Pretest kelas eksperimen lebih rendah dibandingkan nilai rata-rata kelas kontrol 65,20 < 68,00. Adapun setelah dilakukan perlakukan yang berbeda, dimana kelas eksperimen mendapatkan perlakukan dengan proses pembelajaran menggunakan media pembelajaran zoom dan kelas kontrol menggunakan pembelajaran konvensional, diperoleh nilai rata-rata kelas eksperimen lebih tinggi dibandingkan kelas kontrol yaitu $91,00>82,40$.

Adanya perbedaan hasil belajar PPKn pada dua kelas tersebut diasumsikan karena ada perbedaan perlakuan dalam proses

\section{SIMPULAN}

Berdasarkan hasil penelitian dari data yang diperoleh, maka dapat disimpulkan bahwa penggunaan media pembelajaran berpengaruh terhadap hasil belajar PPkn siswa kelas IV di MI Al-Wathoniyah 43. Hal tersebut dapat dibuktikan dari hasil analisis data yang menunjukan bahwa nilai rata-rata postest hasil belajar PPKn pada kelas eksperimen yaitu 91,00, sedangkan untuk pembelajaran. Kedua kelas ini berasal dari populasi yang berdistribusi normal dengan signifikansi pada masing-masing kelas memperoleh lebih dari 0,05 dan memiliki ragam yang sama atau homogen.

Berdasarkan hasil pengujian hipotesis postest terhadap kelas eksperimen dan kelas kontrol dengan menggunakan uji-t dengan taraf signifikansi $5 \%(0,05)$ diperoleh nilai (sig.2-tailed) yaitu 0,44. Dengan demikian dapat disimpulkan bahwa penggunaan media pembelajaran zoom berpengaruh baik terhadap hasil belajar PPKn siswa kelas IV MI Al-Wathoniyah 43 Jakarta Utara.

nilai rata-rata postest hasil belajar pada kelas kontrol yaitu 82,40. Hasil postest tersebut menunjukan bahwa nilai rata-rata kelas eksperimen yang diajarkan dengan menggunakan media zoom lebih tinggi dibandingkan dengan nilai rata-rata kelas kontrol yang diberikan perilaku dengan model pembelajaran konvesional $(91,00>$ $82,40)$. 
Hasil postest tersebut diperkuat dengan hasil pengolahan data menggunakan pengujian hipotesis $(u j i-t)$ menggunakan program SPSS yang memperoleh nilai-niali (sig.2-tailed) dengan taraf signifikansi $5 \% \quad(0,05)$. Hasil pengujian hipotesis $(u j i-t)$ tersebut menunjukan hasil akhir bahwa Ho ditolak dan Ha diterima, maka dapat dikatakan bahwa dapat pengaruh yang siginifikan penggunaan

\section{REFERENCES}

Putra, Rahmat. 2018. Motivasi Berprestasi dan Disiplin Peserta Didik Serta Hubungannya Dengan Hasil Belajar. Kalimantan: Yudha english gallery Susanto, Ahmad. 2013. Teori belajara \& Pembelajaran di sekolah Dasar. Jakarta: PT Prenadamedia Group. Hakim, Thursan. 2010. Belajar Secara Efektif.

Jakarta: Pustaka Pembangunan Swadaya Nusantara.

Haqien, Dani \& Aqilah Afiifadiyah Rahman.

2020. Pemanfaatan Zoom Meeting

Untuk Proses Pembelajaran Pada Masa Pendemi Covid 19. Jurnal Susunan Artikel Pendidikan. Vol 5 No. 1.

Nata, Abuddin. 2009. Perspektif Islam Tentang strategi Pembelajaran. Jakarta: Kencana Prendamedia Group.

Kasmir, Mursyid. 2020. Implementasi zoom, Google Classroom dan Whatsapp Group Dalam Mendukung Pembelajaran Daring(Online) Pada media pembelajaran zoom terdapat hasil belajar PPKn. Hasil angket juga menunjukan bahwa pembelajaran zoom bernilai $86 \%$, berdasarkan hasil tersebut, maka kesimpulan yang dapat diambil dari penelitian ini adalah media pembelajaran zoom berpengaruh terhadap hasil belajar PPKn siswa.

Mata Kuliah Bahasa Inggris. Jurnal AKSARA Public. Vol 4 No. 2.

Kustiawan, Usep. 2016. Pengembangan Media Pembelajaran Anak Usia Dini. Malang: Gunung Samudera

Kustiawan, Usep. 2016. Pengembangan Media Pembelajaran Anak Usia Dini. Malang: Gunung Samudera Jalinus, Nizwardi dan Ambiyar. 2016. Media dan Sumber Pembelajaran. Jakarta: Kencana.

Kasmir, Mursyid. 2020. Implementasi zoom, Google Classroom dan Whatsapp Group Dalam Mendukung Pembelajaran Daring(Online) Pada Mata Kuliah Bahasa Inggris. Jurnal AKSARA Public. Vol 4 No. 2. haruin, Yahya 2020. Evaluasi dan Penilaian dalam Pembelajaran. Yogyakarta: Group Penelitian CV Budi utama 64

triana, Devi Dinny. 2020. Penilaian Kelas dalam Pembelajaran Tari. 
Pengaruh Media Pembelajaran Zoom terhadap Hasil Belajar PPkn...

Surabaya: CV Jakad Media

Publishing. 41

https://trikinet.com/post/apa-itu-zoom 